\title{
Helicobacter pylori infection and childhood recurrent abdominal pain: Lack of evidence for a cause and effect relationship
}

\author{
Colin Macarthur MBChB PhD
}

C Macarthur. Helicobacter pylori infection and childhood recurrent abdominal pain: Lack of evidence for a cause and effect relationship. Can J Gastroenterol 1999;13(7):607-610.

BACKGROUND: Recurrent abdominal pain is a common complaint among children and adolescents. Apley's criteria - at least three discrete episodes of abdominal pain of sufficient severity to interrupt normal activities that occur over a period of three or more months - are often used to define this chronic pain syndrome. OBJECTIVE: To summarize the extent and quality of the published evidence for a cause-and-effect relationship between Helicobacter pylori infection and childhood recurrent abdominal pain. MATERIALS AND METHODS: The MEDLINE bibliographic database (January 1983 to July 1998) was searched to identify pertinent (English language) studies. The search was restricted to prospective, controlled studies reporting empirical data on children up to 18 years of age.

RESULTS: Six studies were identified. Five of the six were casecontrol studies, while the remaining study assessed the effectiveness of antibiotic therapy. Only one study was community based, with the remaining studies conducted in the tertiary hospital setting. The evidence for a causal relationship was inconsistent; of the five case-control studies reviewed, the odds ratios ranged from 0.32 to 1.80 . Two studies demonstrated statistically significant results; however, the findings were conflicting. The only treatment trial was limited because of methodological flaws.

CONCLUSIONS: Current evidence suggests no association between $H$ pylori infection and recurrent abdominal pain in children. The evidence to date indicates that routine investigation for H pylori infection in children who present with the classical symptoms of recurrent abdominal pain based on Apley's criteria is not warranted.

Key Words: Children; Helicobacter pylori; Recurrent abdominal pain

\section{Infection à Helicobacter pylori et douleur} abdominale récurrente chez l'enfant : preuves insuffisantes d'une relation de cause à effet

HISTORIQUE : La douleur abdominale récurrente est une plainte souvent formulée chez les enfants et les adolescents. Les critères d'Appley (au moins trois épisodes distincts de douleur abdominale d'intensité suffisante pour perturber les activités normales et survenant au cours d'une période de trois mois ou plus) sont souvent utilisés pour définir ce syndrome de douleur chronique.

OBJECTIF : Résumer la puissance et la qualité des preuves publiées d'un lien de cause à effet entre l'infection à Helicobacter pylori et la douleur abdominale récurrente chez l'enfant.

MATÉRIEL ET MÉTHODES : La base de données bibliographiques MEDLINE (janvier 1983 à juillet 1998) a été interrogée pour identifier les études pertinentes en langue anglaise. Cette interrogation a été limitée aux études prospectives contrôlées faisant état de données empiriques sur des enfants âgés de 18 ans au maximum.

RÉSULTATS : Six études ont été identifiées. Cinq de ces études étaient des études avec cas/témoin, alors que la dernière cherchait à évaluer l'efficacité de l'antibiothérapie. Une seule étude était basée dans la communauté, alors que les autres ont été menées dans le contexte d'un établissement de soins tertiaires. Les preuves d'un lien de cause à effet se sont révélées aléatoires. Parmi les cinq études cas/témoins passées en revue, le risque relatif variait de 0,32 à 1,80 . Deux études ont fait état de résultats statistiquement significatifs, mais diamétralement opposés. La pertinence du seul essai thérapeutique a été limitée par des lacunes méthodologiques. CONCLUSIONS : Les preuves actuelles ne permettent pas d'établir un lien entre l'infection à $H$. pylori et la douleur abdominale récurrente chez les enfants. À ce jour, les preuves indiquent que le dépistage systématique de $H$. pylori chez les enfants qui présentent des symptômes classiques de douleur abdominale récurrente sur la base des critères d'Appley n'est pas justifié.

Departments of Community Health Sciences and Paediatrics, University of Calgary, Calgary, Alberta

Correspondence and reprints: Dr Colin Macarthur, Department of Community Health Sciences, Health Sciences Centre, 3330 Hospital Drive NW, Calgary, Alberta T2N 4N1. Telephone 403-220-8585, fax 403-270-7307, e-mail colinmac@ucalgary.ca 
$\mathrm{R}$ ecurrent abdominal pain is a common complaint among children and adolescents. Apley's criteria - at least three discrete episodes of abdominal pain of sufficient severity to interrupt normal activities and occurring over a period of three or more months - are often used to define this chronic pain syndrome (1). Several descriptive studies have shown that the prevalence of recurrent abdominal pain ranges from $10 \%$ to $15 \%$ in schoolchildren (1-3). Peak prevalence occurs at around nine years of age, with a slightly higher prevalence in females than in males (4). Survey data also demonstrate that recurrent abdominal pain is a common presenting complaint to primary care physicians and subspecialists $(5,6)$. In addition, the pain syndrome is associated with frequent school absences (7).

The etiology and pathogenesis of recurrent abdominal pain are, however, poorly understood. Although early reports implicated psychological factors, subsequent controlled studies failed to demonstrate a clear psychological etiology for this chronic pain syndrome (8-10). The initial focus on possible psychological causes was driven, in part, by the low frequency of identifiable 'organic' causes in children with recurrent abdominal pain. Most studies suggest that less than $10 \%$ of children with recurrent abdominal pain have an organic etiology for their chronic pain (11-14).

The discovery of Helicobacter pylori and its association with antral gastritis in children stimulated interest in the possibility of an infectious etiology for recurrent abdominal pain (15). A previous review of the published literature on $H$ pylori infection and recurrent abdominal pain, however, demonstrated inconsistent results (16). In addition, the evidence at that time was limited to case series (only one controlled study was identified), study populations were heterogeneous, and only children referred to tertiary centres were studied. Subsequent controlled studies have addressed some of these limitations $(17-22)$. Therefore, the objective of this critical review was to summarize the extent and quality of the current published evidence for a cause-and-effect relationship between $H$ pylori infection and childhood recurrent abdominal pain.

\section{MATERIALS AND METHODS}

The MEDLINE bibliographic database (January 1983 to July 1998) was searched to identify pertinent studies. Only English language publications were included. Medical subject key headings included 'Campylobacter pyloridis', 'Campylobacter pylori', 'Helicobacter pylori', 'abdominal pain' and 'recurrent abdominal pain'. Current Contents and selected pediatric and gastroenterology journals were also searched. Relevant citations from the bibliographies of identified articles were also retrieved.

The search was restricted to prospective, controlled studies reporting empirical data on children ( 0 to 18 years of age). Editorials, commentaries, reviews, case reports, case series and letters to the editor were excluded. The published data were used to estimate the prevalence of $H$ pylori infection in children with recurrent abdominal pain and in control children. These data were used to calculate an odds ratio for each study, with $95 \%$ confidence intervals derived using the test-based method (23). (In most situations, the odds ratio provides a good approximation of the relative risk, ie, the risk of recurrent abdominal pain in children with $H$ pylori infection, compared with the risk in uninfected children.)

To assess the quality of the evidence, information pertinent to the internal and external validity of each study was gathered. Such data included study design, setting, criteria for case definition, selection of controls, sample size, validity of measures, control for confounding variables, number of subjects lost to follow-up and blinding of investigators (where appropriate). Last, several of Hill's criteria for causal inference were applied to the published data to assess the strength of the evidence for a causal relationship between $H$ pylori infection and recurrent abdominal pain $(16,24)$. Criteria applied included strength of the association, consistency, temporality, biological plausibility and experimental evidence.

\section{RESULTS}

Six prospective, controlled studies that examined the association between $H$ pylori infection and childhood recurrent abdominal pain were identified (17-22). Five of the six were case-control studies, ie, sampling was on outcome status, whereby children with recurrent abdominal pain were compared with control children (17-21). The prevalence of $H$ pylori infection in the group with recurrent abdominal pain was then compared with the prevalence of $H$ pylori infection in control children. The remaining study assessed the effectiveness of antibiotic therapy in children with recurrent abdominal pain (22).

The characteristics of the five case-control studies are shown in Table 1. The studies were worldwide; however, only one study was truly community-based (21), with the remaining studies conducted in the tertiary care hospital setting (17-20). Each of the studies used (modified) Apley's criteria to define cases (children with recurrent abdominal pain). Control children were selected from outpatient clinics (both gastroenterology and nongastroenterology), preoperative clinics, day surgery lists and schools. All the studies measured $H$ pylori infection by using serological tests.

Table 2 shows the prevalence of $H$ pylori infection in children with recurrent abdominal pain and in control children. As shown by the odds ratios, study results were inconsistent. Results from three studies were not significant, ie, the 95\% confidence intervals included unity. Results from two studies were statistically significant but were conflicting. The study by Chong et al (19) suggested that $H$ pylori infection was a risk factor for recurrent abdominal pain, whereas the study by Hardikar et al (20) suggested that infection was protective against recurrent abdominal pain. Of note, of all the studies, only Hardikar et al (20) controlled for potential confounding variables. In their study, multivariate analysis was used to control for age, sex, parental ethnicity and socioeconomic status. The adjusted odds ratio was 0.21 (95\% CI 0.05 to 0.85 ).

The single treatment trial used triple therapy (amoxicil- 
TABLE 1

Characteristics of published case-control studies examining the association between Helicobacter pylori infection and childhood recurrent abdominal pain

\begin{tabular}{|c|c|c|c|c|}
\hline Author (reference) & Country & Setting & Case definition & Source of controls \\
\hline van der Meer et al (17) & The Netherlands & Tertiary hospital & $\begin{array}{l}5 \text { to } 12 \text { years of age; } 6 \text {-month history } \\
\text { of intermittent abdominal pain; } \\
\text { vegetative symptoms }\end{array}$ & $\begin{array}{l}\text { Preoperative clinics and outpatient } \\
\text { clinics (nongastroenterology) }\end{array}$ \\
\hline McCallion et al (18) & Northern Ireland & Tertiary hospital & $\begin{array}{l}\geq 1 \text { episode of abdominal pain/month } \\
\text { over } \geq 3 \text { months severe enough to } \\
\text { miss school or see a physician }\end{array}$ & Day surgery patients \\
\hline Chong et al (19) & United States & Tertiary hospital & $\begin{array}{c}\geq 3 \text { episodes of abdominal pain over a } \\
\text { 3-month period severe enough to } \\
\text { interfere with normal activities }\end{array}$ & $\begin{array}{l}\text { Gastrointestinal disease outpatient } \\
\text { clinic }\end{array}$ \\
\hline Hardikar et al (20) & Australia & Tertiary hospital & $\begin{array}{l}5 \text { to } 12 \text { years of age; } \geq 3 \text { episodes of } \\
\text { abdominal pain over a 3-month } \\
\text { period severe enough to interfere } \\
\text { with daily activity; not previously } \\
\text { seen by pediatrician or } \\
\text { subspecialist }\end{array}$ & $\begin{array}{l}\text { Day surgery patients ( } 5 \text { to } 12 \text { years of } \\
\text { age) without gastrointestinal } \\
\text { symptoms, recurrent abdominal } \\
\text { pain or family history of peptic } \\
\text { ulcer disease }\end{array}$ \\
\hline O'Donohoe et al (21) & United Kingdom & Community & $\begin{array}{l}\geq 3 \text { episodes of abdominal pain in } \\
\text { previous year severe enough to } \\
\text { interfere with daily life; onset } \geq 3 \\
\text { months before the study }\end{array}$ & $\begin{array}{l}\text { School-aged children (no history of } \\
\text { abdominal pain) }\end{array}$ \\
\hline
\end{tabular}

TABLE 2

Prevalence of Helicobacter pylori infection in children with recurrent abdominal pain and in control children

Cases
Controls

$\begin{array}{cc}\mathbf{( 9 5} \% \mathbf{C I}) & \text { Reference } \\ 1.73(0.35-8.64) & 17 \\ 1.10(0.63-1.90) & 18 \\ 1.80(1.05-3.08) & 19 \\ 0.32(0.11-0.94) & 20 \\ 0.49(0.23-1.05) & 21\end{array}$

H pylori+ Helicobacter pylori-positive; n/a Data not available

lin, bismuth subcitrate and metronidazole) in a subset of children with both $\mathrm{H}$ pylori infection and recurrent abdominal pain (22). Around 20\% of children were lost to followup, assessments were not blinded and the psychometric properties of the measure used to quantify abdominal pain were not provided. Last, and of most concern (as noted by the authors), there was no placebo control group.

Application of Hill's criteria to the published data demonstrated that the association between $H$ pylori infection and recurrent abdominal pain was not strong; results were inconsistent, there was no evidence for a temporal relationship, no biological plausibility and no supporting experimental evidence.

\section{DISCUSSION}

The evidence for a causal relationship between $H$ pylori infection and recurrent abdominal pain is inconsistent. Of the five studies reviewed, the odds ratios ranged from 0.32 to
1.80. Two studies demonstrated statistically significant results; however, the findings were conflicting. The only treatment trial was limited because of methodological flaws.

Although the literature search was comprehensive, some studies (both published and unpublished) may have been missed. Furthermore, only (English language) publications were reviewed. Last, information pertinent to the review and collected by the investigators may not have been provided in the journal article.

Of the five case-control studies, results from three were not significant, whereas one demonstrated a statistically significant negative association. In other words, the weight of the evidence suggests no association between $H$ pylori infection and recurrent abdominal pain. The study by Chong et al (19), however, suggested an increased risk of recurrent abdominal pain in children with $H$ pylori infection. The validity and generalizability of these findings, however, may be limited. First, the study was conducted in a tertiary hospital 
setting. Therefore, although endoscopy was performed on only 111 of 218 children with recurrent abdominal pain, 14 $(13 \%)$ had duodenal or gastric ulcer disease. In addition, the control children were selected from those attending a gastroenterology clinic for reasons other than recurrent abdominal pain. As expected, many of these children demonstrated gastrointestinal pathology. For example, 51 of the control children had chronic liver disease, 48 had chronic inflammatory bowel disease, 24 had failure-to-thrive and 22 had gastrointestinal bleeding. In summary, the case group was not representative of all children with recurrent abdominal pain, while the control group of children was not a suitable comparison group. Last, there was no adjustment for potential confounding variables, such as age, ethnicity and socioeconomic status.

The study by Hardikar et al (20) showing a statistically significant negative association between $\mathrm{H}$ pylori infection and recurrent abdominal pain has several strengths (20). First, only incident cases of recurrent abdominal pain were recruited. In addition, control children (selected from day surgery lists) were in good health, with no history of recurrent abdominal pain or other gastrointestinal symptoms, and no family history of peptic ulcer disease. Also, the serological test had been validated in the specific age group and population that was studied. Moreover, the investigators controlled for potential confounding variables (age, sex, ethnicity and socioeconomic status) by using multivariate analysis.

Calculation of a summary odds ratio across all studies was not a primary aim of this review. Given the heterogeneity of study populations and the inclusion of only observational study designs in the review, cautious interpretation of any summary estimate of effect is necessary. The Mantel-

\section{REFERENCES}

1. Apley J, Naish N. Recurrent abdominal pains: a field survey of 1,000 school children. Arch Dis Child 1958;33:165-70.

2. Oster J. Recurrent abdominal pain, headache and limb pains in children and adolescents. Pediatrics 1972;50:429-36.

3. Dodge JA. Recurrent abdominal pain in children. Br Med J 1976;1:385-7.

4. Scott RB. Recurrent abdominal pain during childhood. Can Fam Physician 1994;40:539-47.

5. Nicol AR. Psychogenic abdominal pain in childhood. Br J Hosp Med 1982;27:351-3.

6. Adelman AM, Koch H. New visits for abdominal pain in the primary care setting. Fam Med 1991;23:122-6.

7. Liebman WM. Recurrent abdominal pain in children: a retrospective survey of 119 patients. Clin Pediatr 1978;17:149-53.

8. Raymer D, Weininger O, Hamilton J. Psychological problems in children with abdominal pain. Lancet 1984;1:439-40.

9. McGrath P, Feldman W. Clinical approach to recurrent abdominal pain in children. J Dev Behav Pediatr 1986;7:56-61.

10. Robinson J, Alvarez J, Dodge J. Life events and family history in children with recurrent abdominal pain. J Psychosom Res 1990;34:171-81.

11. Apley J. A common denominator in recurrent pains of childhood. Proc R Soc Med 1958;51:1023-4.

12. Stone RT, Barbero GJ. Recurrent abdominal pain in childhood. Pediatrics 1970;45:732-8.

13. Bury RG. A study of 111 children with recurrent abdominal pain. Aust Paediatr J 1987;23:117-9.

14. van der Meer SB, Forget PP, Arends JW, Kuijten RH, van Engelshoven JMA. Diagnostic value of ultrasound in children with recurrent abdominal pain. Pediatr Radiol 1990;20:501-3.
Haenszel method for pooling data across studies was used (24). Of note, the $\chi^{2}$ test for heterogeneity of odds ratios was positive, ie, the Chong study odds ratio was significantly different from the odds ratios estimated by the remaining four studies. Calculation of a summary estimate of effect (after exclusion of the Chong study) resulted in a summary odds ratio of 0.74 ( $95 \%$ CI 0.50 to 1.10 ).

Treatment trials are an alternative approach to examining the association between $H$ pylori infection and recurrent abdominal pain. In other words, if the association were causal, it would be expected that eradication of $H$ pylori infection would lead to resolution of symptoms. Causal inference from treatment trials is strengthened when allocation to treatment or placebo is random, investigators and patients are blinded to group assignment, loss to follow-up is minimized, and outcome measures are standardized and valid. The single treatment trial identified by this review, however, did not meet any of these criteria (22).

\section{CONCLUSIONS}

The weight of the current evidence suggests no obvious association between $H$ pylori infection and recurrent abdominal pain in children. The results, however, are inconsistent. Further evidence from community-based studies, using healthy children as controls, with adjustment for potential confounders, is needed. Therefore, evidence to date indicates that routine investigation for $\mathrm{H}$ pylori infection in children who present with the classical symptoms of recurrent abdominal pain (based on Apley's criteria) is not warranted. Similarly, treatment of the infection to resolve symptoms of recurrent abdominal pain is not justified.

15. Farrell M. Dr. Apley meets Helicobacter pylori. J Pediatr Gastroenterol Nutr 1993;16:118-9.

16. Macarthur C, Saunders N, Feldman W. Helicobacter pylori, gastroduodenal disease, and recurrent abdominal pain in children. JAMA 1995;273:729-34.

17. van der Meer SB, Forget PP, Loffeld RJ, Stobberingh E, Kuijten RH, Arends JW. The prevalence of Helicobacter pylori serum antibodies in children with recurrent abdominal pain. Eur J Pediatr 1992;151:799-801.

18. McCallion WA, Bailie AG, Ardill JE, Bamford KB, Potts SR, Boston VE. Helicobacter pylori, hypergastrinaemia and recurrent abdominal pain in children. J Pediatr Surg 1995;30:427-9.

19. Chong SK, Lou Q, Asnicar MA, et al. Helicobacter pylori infection in recurrent abdominal pain in childhood: comparison of diagnostic tests and therapy. Pediatrics 1995;96:211-5.

20. Hardikar W, Feekery C, Smith A, Oberklaid F, Grimwood K. Helicobacter pylori and recurrent abdominal pain in children. J Pediatr Gastroenterol Nutr 1996;22:148-52.

21. O'Donohoe JM, Sullivan PB, Scott R, Rogers T, Brueton MJ, Barltrop D. Recurrent abdominal pain and Helicobacter pylori in a community-based sample of London children. Acta Paediatr 1996;85:961-4

22. Heldenberg D, Wagner Y, Heldenberg E, et al. The role of Helicobacter pylori in children with recurrent abdominal pain. Am J Gastroenterol 1995;90:906-9.

23. Schlesselman JJ. Case-Control Studies. Design, Conduct, Analysis, 1st edn. New York: Oxford University Press, 1982:206-7.

24. Petitti DB. Meta-Analysis, Decision Analysis, and Cost-Effectiveness Analysis. Methods for Quantitative Synthesis in Medicine, 1st edn. New York: Oxford University Press, 1994:96-9. 


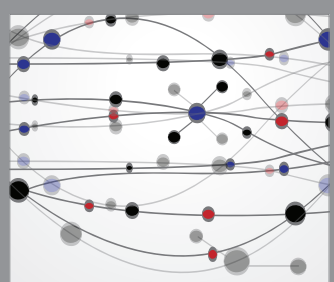

The Scientific World Journal
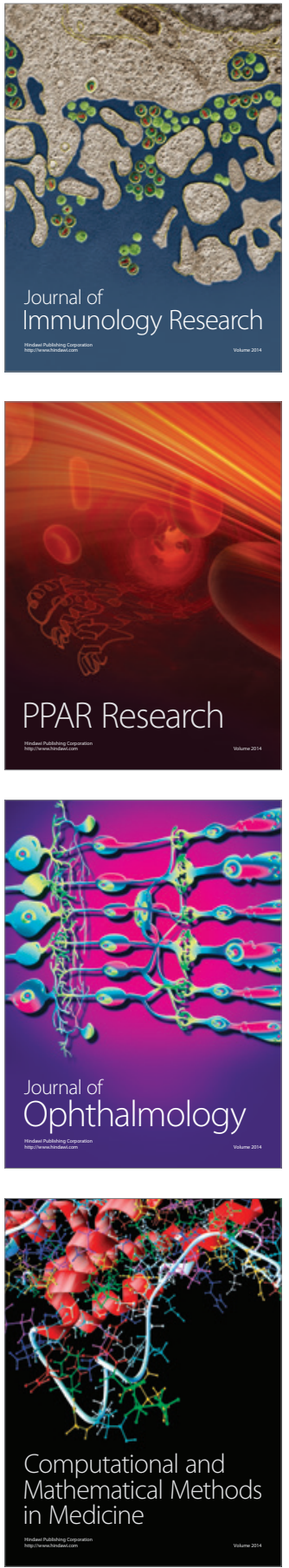

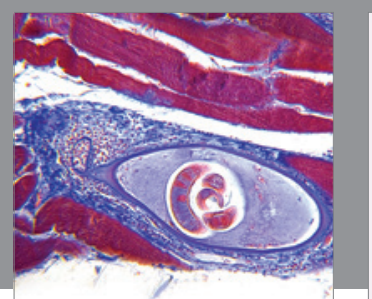

Gastroenterology Research and Practice

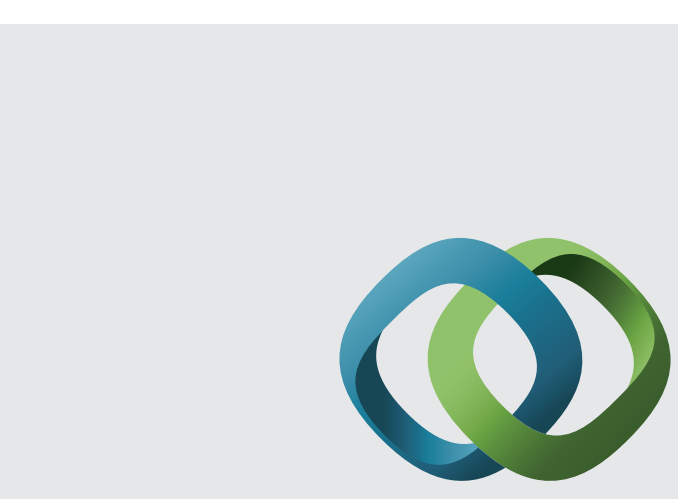

\section{Hindawi}

Submit your manuscripts at

http://www.hindawi.com
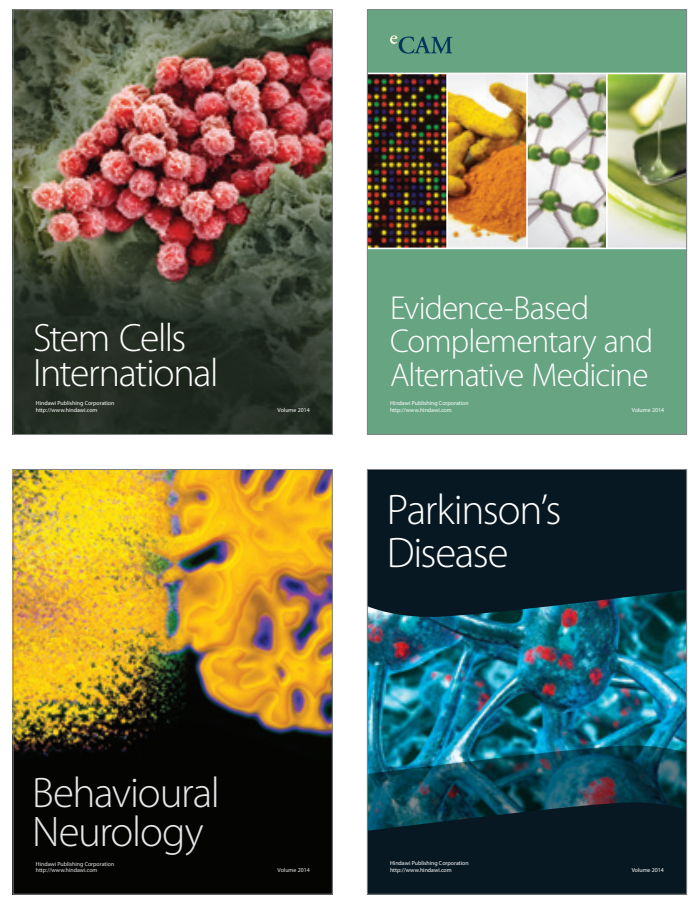
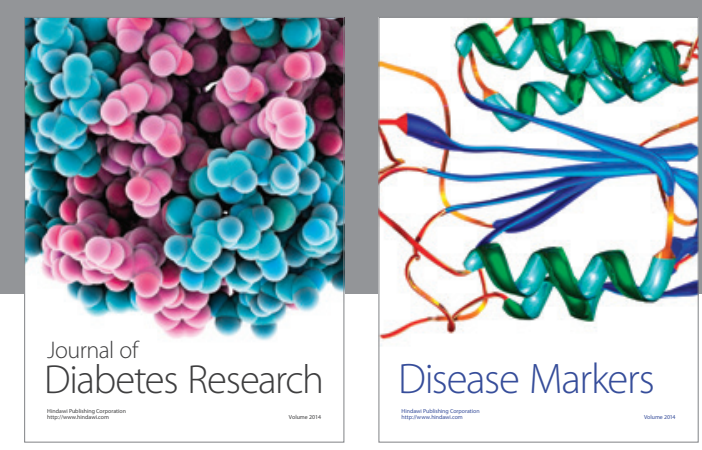

Disease Markers
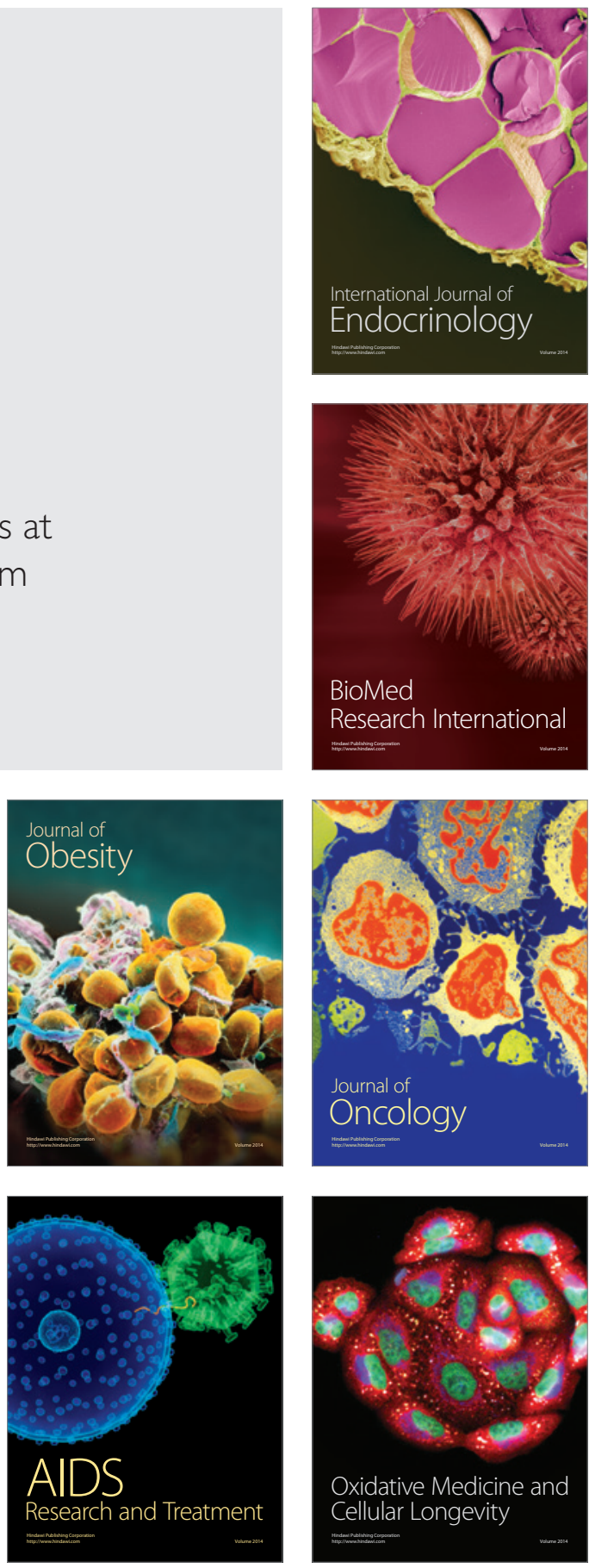